\title{
Medievalista
}

Online

$26 \mid 2019$

Número 26

Tese de doutoramento em História, apresentada à Faculdade de

Letras da Universidade do Porto, Maio de 2018. Orientação da

Professora Doutora Paula Pinto Costa

\section{Pedro Álvares Seco: a retroprojeção da memória da Ordem de Cristo no século XVI}

Tese de doutoramento em História, apresentada à Faculdade de Letras da Universidade do Porto, Maio de 2018. Orientação da Professora Doutora

Paula Pinto Costa

\section{Joana Lencart}

\section{(2) OpenEdition}

\section{Journals}

Edição electrónica

URL: http://journals.openedition.org/medievalista/2740

DOI: $10.4000 /$ medievalista. 2740

ISSN: 1646-740X

\section{Editora}

Instituto de Estudos Medievais - FCSH-UNL

Edição impressa

Data de publição: 1 junho 2019

\section{Refêrencia eletrónica}

Joana Lencart, «Pedro Álvares Seco: a retroprojeção da memória da Ordem de Cristo no século XVI », Medievalista [Online], 26 | 2019, posto online no dia 27 julho 2019, consultado o 23 setembro 2020. URL : http://journals.openedition.org/medievalista/2740; DOI : https://doi.org/10.4000/medievalista. 2740

\section{(c) (i) (5)}

Mediavalista está licenciado com uma Licença Creative Commons - Atribuição-NãoComercial 4.0 Internacional. 
Título / Title: Pedro Álvares Seco: a retroprojeção da memória da Ordem de Cristo no século XVI

Tese de doutoramento em História, apresentada à Faculdade de Letras da Universidade do Porto, Maio de 2018. Orientação da Professora Doutora Paula Pinto Costa

Autor(es) / Author(s): Joana Lencart

Afiliação institucional / Institutional affiliation (Unidade de Investigação, Faculdade, Departamento, Universidade, Código postal, Cidade, País): Faculdade de Letras, Universidade do Porto, 4150-564, Porto, Portugal

Email Institucional / Institutional email: joana.lencart@meo.pt

Fonte: Medievalista [Em linha]. Direc. Bernardo Vasconcelos e Sousa. Lisboa: IEM.

Disponível em:

http://www2.fcsh.unl.pt/iem/medievalista/MEDIEVALISTA26/farelo2613.html

ISSN: 1646-740X

Data recepção do artigo / Received for publication: 17 de abril de 2019 


\section{$3^{6}$}

\section{Pedro Álvares Seco: a retroprojeção da memória da Ordem de Cristo no século XVI}

\section{Joana Lencart}

O título deste trabalho, "Pedro Álvares Seco: a retroprojeção da memória da Ordem de Cristo no século XVI"1, aponta para um duplo protagonismo, por um lado, Pedro Álvares Seco, autor e cronista, e, por outro, a Ordem de Cristo no século XVI. Também duplo é o seu sentido, expresso nos conceitos: retroprojeção e memória. Neste contexto, o termo retroprojeção foi usado por Luís Adão da Fonseca: "recordar é sempre, em alguma medida, projetar. No caso da memória histórica, esta é, efetivamente, uma retroprojeção que nos fornece preciosas informações a respeito dos propósitos mais profundos de quem, em determinado momento, organiza as suas recordações"”. Sintetiza, assim, o exercício feito pelo cronista da Ordem de Cristo a partir do seu presente: a fixação de uma memória da Ordem, redigida no século XVI, que fundamenta no passado - a Ordem do Templo - uma imagem que pretende projetar para o futuro. Neste sentido, é, simultaneamente, uma memória histórica e uma memória do poder, neste caso concreto, do poder do rei que é paralelamente o governador da Ordem e, como tal, promotor do ambicioso projeto levado a cabo por Álvares Seco. Este assume que as suas obras se fazem para que fique memória e prova, conferindo-lhes um valor jurídico-administrativo e probatório como se depreende das suas palavras: "porque essa he a causa porque se faz este livro pera memoria e prova" 3 .

Vários princípios estiveram subjacentes à realização deste trabalho. Primeiro, era preciso definir os motivos que levaram o cronista Pedro Álvares Seco a elaborar tamanha produção documental. Segundo, inventariar as fontes da sua autoria, tarefa

\footnotetext{
${ }^{1}$ Disponível em http://catalogo.up.pt/F/?func=direct\&doc_number=000872197\&local_base=FLUP.

2 FONSECA, Luís Adão da - "A Memória das Ordens Militares: o Livro dos Copos da Ordem de Santiago". As Ordens Militares em Portugal. Palmela: Câmara Municipal de Palmela, 1991, p 15.

${ }^{3}$ ANTT, Ordem de Cristo/Convento de Tomar, liv. 2, fl. 10r.
} 
árdua, de certa forma, pois não se tratou apenas de um trabalho arquivístico circunscrito a esses documentos, na medida em que implicou também a identificação e a elaboração de uma lista completa dos fundos documentais da Ordem de Cristo, no sentido de se poder aferir a dimensão da obra em estudo. Terceiro, analisar a documentação destinada a proceder ao levantamento dos indícios documentais e à análise criteriosa das obras da sua autoria. Quarto, reunir os indícios documentais que permitiram dar resposta à questão inicial, a par do contexto de produção das obras. Quinto, classificar e ordenar, de modo a poder interpretar esses indícios e responder à questão inicial. Sexto, redigir um texto que exprimisse de forma adequada os factos sugeridos pelas fontes documentais e interpretar o seu sentido, respondendo às questões colocadas.

As palavras-chave definidas para este trabalho são Pedro Álvares Seco, Ordem de Cristo, século XVI, memória histórica e produção documental. O objetivo que está subjacente é, assim, sistematizar e interpretar o significado da obra de Pedro Álvares Seco no contexto da Ordem de Cristo, no século XVI. Esta Ordem, se bem que herdeira patrimonial dos Templários, é uma criação da monarquia como instituição refletora da realeza.

A principal dificuldade que se colocou para a concretização deste trabalho foi, numa primeira fase, a identificação das obras da autoria de Pedro Álvares Seco e, na sequência desta, a sua localização em arquivos e bibliotecas. Outra questão com que também nos deparámos foi o acesso às referidas obras, devido ao mau estado de conservação de algumas delas, o que nos impediu de consultar uma obra. Um desafio ainda mais intricado, do que a localização e o acesso às fontes, foi a sua difícil interpretação e, nalguns casos, a aferição da sua fiabilidade, quanto à autoria.

Refletindo sobre o estado de arte, podemos afirmar que foi em finais do século XVI que começaram a ser produzidos, relativamente a Portugal, escritos de cunho discursivo e historiográfico respeitantes à temática das Ordens Militares, de que o primeiro autor é Jerónimo Román. Por sua vez, as publicações que surgiram entre meados do século XIX e meados do século XX são sobretudo de caráter geral, e consistem nas histórias monumentais de Portugal que incluem a temática dos Templários e da Ordem de Cristo. Nas últimas décadas, estas Ordens têm sido objeto de estudos monográficos por parte de 
diversos autores, que muito contribuíram para enriquecer o conhecimento científico relativo a esta temática. A interpretação do espólio documental de Pedro Álvares Seco terá em consideração as mais recentes linhas da historiografia e da teoria da história, domínio em que há uma clara recuperação da figura humana, até numa perspetiva biográfica, e da história institucional, com base na reinterpretação dos documentos.

A estrutura deste trabalho reflete uma divisão em duas partes. De seguida, descrevemse, brevemente, os assuntos versados em cada uma.

Na primeira parte, intitulada "A Ordem de Cristo desde a sua fundação até 1581", não se pretende fazer uma súmula de aspetos já abordados em outras obras sobre Ordens Militares (e referidos no Estado da Arte), mas o objetivo é fornecer o enquadramento histórico e institucional necessário à contextualização da obra de Álvares Seco.

Assim, no primeiro capítulo da primeira parte é abordada a evolução histórica da Ordem em três fases, articuladas com o discurso de Pedro Álvares, desde a sua fundação, em 1319, até à morte do cronista, em 1581. A repartição em três fases resultou da identificação de momentos-chave na história da Ordem de Cristo e que marcaram atuações distintas por parte dos seus protagonistas. A primeira fase, de 1319 a 1420 , subordina-se ao período que decorre entre a criação da Ordem de Cristo e a nomeação do infante D. Henrique como seu administrador. Neste primeiro período a instituição é regida por Mestres que são, efetivamente, freires cavaleiros da Ordem. A segunda fase, entre 1420 e 1529, é balizada pela administração da Ordem de Cristo por parte do infante D. Henrique e a nomeação de Fr. António de Lisboa como reformador desta instituição, em junho de 1529, ordenada por D. João III. É a fase da afirmação clara da tutela régia sobre a Ordem de Cristo. A terceira fase, entre 1529 e 1581, coincide com a reforma da Ordem de Cristo levada a cabo por Fr. António de Lisboa. É também o período de produção das obras de Pedro Álvares Seco, até à sua morte, em 1581.

No segundo capítulo é feita uma reflexão sobre a organização da instituição, tanto a nível eclesiástico, como a nível patrimonial e administrativo, tendo sempre presente a sua articulação com a obra do cronista. Justifica-se a inserção desta temática nesta tese em virtude de a obra coligida por Pedro Álvares Seco estar orientada em ambos estes 
sentidos: a dimensão histórico-institucional, que reflete a organização eclesiástica das instituições, e a dimensão patrimonial e económica, onde está plasmada a organização administrativa das Ordens Militares.

A segunda parte intitula-se "Pedro Álvares Seco: a época, a vida e a obra", e divide-se em sete capítulos. Cronologicamente, abarca o período entre os anos 20 e os anos 80 do século XVI, correspondendo, o início, grosso modo, à sua nomeação como professor de cânones do convento de Tomar, em 1521, e o final, à sua morte, em 1581.

No primeiro capítulo é feita uma resenha da época histórica em que Pedro Álvares executou a sua obra. Há acontecimentos e momentos que importam destacar em virtude da sua estreita relação com o tema em estudo, concretamente a relação entre o papado e a monarquia portuguesa no que diz respeito às Ordens Militares. Refira-se que, desde 1514 , o papa Leão X concedeu a D. Manuel o direito de padroado régio sobre todas as igrejas do império ultramarino; em 1516, o rei alcança o padroado das igrejas das três Ordens Militares, Cristo, Avis e Santiago; e, finalmente, D. João III, em 1551, é nomeado pelo papa como administrador perpétuo das três Ordens Militares. A partir da década de 1540, D. João III promulgou os alvarás régios que ordenaram a Pedro Álvares Seco a execução de várias obras que preconizaram o levantamento da propriedade e bens da Ordem de Cristo. Da regência de D. Catarina datam os alvarás régios que ordenaram a realização do Livro das Escrituras da Ordem de Cristo e do Livro das Comendas da Ordem de Cristo. Do reinado de D. Sebastião, concretamente de 1571, data o alvará que ordena a Pedro Álvares a redação do Livro das Igrejas e Padroados da Ordem de Cristo. Do curto reinado do cardeal D. Henrique, em particular de 1579, data a concretização da última obra de Pedro Álvares Seco, o Livro da Regra e Definições da Ordem de Cristo, com privilégios, indulgências e graças atribuídos pelos pontifices e reis. Neste primeiro capítulo, é ainda analisada de modo particular a reforma da Ordem de Cristo levada a cabo por Fr. António de Lisboa, a sua atuação no convento de Tomar e o modo como a mesma foi recebida pelos freires do convento. É ainda estudada a atuação de Pedro Álvares Seco durante o priorado de Fr. António de Lisboa no referido convento de Tomar. 
No segundo capítulo desta segunda parte é feita uma análise dos elementos biográficos que identificamos para este cronista. A sua biografia está longe de gerar consenso entre os autores antigos e os mais recentes. Parece, no entanto, consensual ter sido professor de cânones no convento de Tomar, procurador da Ordem de Cristo, cavaleiro professo, contador do mestrado, desembargador régio, ter sido casado com Beatriz Lopes e ter tido filhos. Terá nascido em finais do século XV e morrido em 1581, encontrando-se enterrado na igreja de Santa Maria dos Olivais, em Tomar.

No terceiro capítulo, avaliamos as condições da produção documental, a recolha e a seleção da informação, bom como a metodologia usada pelo cronista. Surgem então várias questões. Como é que o cronista procedeu à recolha da informação, quem o acompanhou nas suas deslocações, como seria o scriptorium onde desenvolveu o trabalho? Haveria um scriptorium organizado no convento, onde os responsáveis pela ars scribendi se aliavam aos iluminadores e encadernadores para produzir as obras da responsabilidade de Pedro Álvares? Intriga-nos como seria a sua mesa de trabalho, os materiais de escrita e de iluminação dos livros; os auxiliares que o rodeavam; teria os pergaminhos e papéis organizados ou dispersos por vários móveis ou mesas; haveria azáfama ou calmaria no cartório aquando da redação dos livros, como era feito o transporte das escrituras e dos livros... questões e dúvidas que tentamos responder ao longo do capítulo.

Identificámos e analisámos o espólio documental elaborado por Pedro Álvares Seco entre 1530 e 1581, num total de 15 obras conhecidas da forma que se segue: Começo e preâmbulo do tombo dos bens, rendas, direitos e escrituras do Convento de Tomar ${ }^{4}$; o Tombo dos bens, rendas, direitos e escrituras do Convento de Tomar ${ }^{5}$; o Tombo dos bens, rendas e direitos que a Mesa Mestral da Ordem de Cristo tem nas vilas de Tomar e Pias e seus termos ${ }^{6}$; o Tombo da igreja de Santa Maria dos Olivais $^{7}$; o Tombo dos bens e propriedades das capelas e aniversários que se cantavam no Convento de Tomar $^{8}$; o Tombo dos bens da Gafaria da Misericórdia de Tomar ${ }^{9}$; o Livro das

\footnotetext{
${ }^{4}$ ANTT, Manuscritos da Livraria, $\mathrm{n}^{\mathrm{o}} 1050$.

${ }^{5}$ ANTT, OC/CT, liv. 232.

${ }^{6}$ ANTT, OC/CT, liv. 2.

${ }^{7}$ ADSTR, Diocesanos, Colegiada de Santa Maria dos Olivais de Tomar, liv. 1.

${ }^{8}$ ANTT, OC/CT, liv. 3.
} 
Escrituras do Hospital de Santa Maria da Graça de Tomar ${ }^{10}$; o Compêndio das Comendas da Ordem de Cristo ${ }^{11}$; o Livro das Comendas da Ordem de Cristo ${ }^{12}$; o Livro de bulas e letras apostólicas concedidas à Ordem de Cristo ${ }^{13}$; o Livro das Escrituras da Ordem de Cristo ${ }^{14}$; a Suma do que se contém no Livro das Igrejas, padroados e direitos eclesiásticos da Ordem de Cristo ${ }^{15}$; o Livro das igrejas, padroados e direitos eclesiásticos da Ordem de Cristo ${ }^{16}$; o Livro dos Sumários das Escrituras da Ordem de Cristo $^{17}$; e o Livro da Regra e Definições da Ordem de Cristo, com privilégios, indulgências e graças atribuídos pelos pontífices e reis ${ }^{18}$. Pedro Álvares Seco foi um produtor de memória, em particular, da memória da Ordem de Cristo. São quinze títulos que, na realidade correspondem a mais de 20 manuscritos, em virtude de terem sido feitas cópias de alguns deles. De uma maneira geral, são obras que, a par de uma redação e contextualização histórica do assunto que cada uma delas versa, transcrevem perto de duas mil escrituras respeitantes às Ordens do Templo e de Cristo, e que revelam não só a formação eclesiástica e jurídica de Álvares Seco, mas também o seu pensamento.

Para elaborar a sua obra monumental, Pedro Álvares Seco baseou-se em diversos testemunhos. Além dos trabalhos de demarcação e inventário a que procedeu quando era procurador e juiz da Ordem de Cristo, e da inquirição de testemunhas, consultou também os cadernos e tombos resultantes de visitações antigas, diversos códices e documentos avulsos do cartório do convento de Tomar, bem como documentação da Torre do Tombo, em Lisboa. O cronista procurava sempre localizar as escrituras originais dos documentos que copiava nos diferentes livros, mas, não o conseguindo, fazia uso de outras disponíveis para validar as suas afirmações, o que demonstra um trabalho feito com rigor. Com tanta informação disponível, Pedro Álvares selecionava a documentação. O processo era complexo. Temos por isso documentos repetidos em

\footnotetext{
${ }^{9}$ AMT, liv. 74, fls. 119r-126r.

${ }^{10}$ AMT, liv. 83.

${ }^{11}$ ANTT, OC/CT, liv. $240\left(19^{\mathrm{A}}\right)$.

12 BNP, Fundo Geral, no 226.

${ }^{13}$ ANTT, OC/CT, liv. 15.

${ }^{14}$ ANTT, OC/CT, liv. 234 e liv. 235 e com cópia em BNP, Fundo Geral, nº 735, nº 736, no 737 e no 738. Livro que é considerado o cartulário da Ordem de Cristo.

${ }^{15}$ ANTT, OC/CT, mç. 52, no 1485.

${ }^{16}$ ANTT, OC/CT, liv. 1, com cópia em ANTT, OC/CT, liv. 11 e BNP, Fundo Geral, no 739.

${ }^{17}$ ANTT, OC/CT, liv. 14.

${ }^{18}$ BNE, mss. 406.
} 
vários livros. Em contrapartida, conhecemos diversos documentos relativos à história da Ordem de Cristo que Álvares Seco não incluiu na composição das suas obras. A seleção documental do autor implicou, obrigatoriamente, esquecimento, conduzindo-nos, de forma inevitável, e na assertiva expressão de Vitorino Magalhães Godinho, ao "naufrágio da memória"19.

Pedro Álvares, para executar esta grandiosa tarefa da edificação da história da Ordem de Cristo, foi auxiliado por diversos escrivães e iluminadores. Os escrivães do convento destacados para a realização da empresa foram João de Penafiel, Bartolomeu de Almeida, Gaspar Garro, Pedro Luís Ortega, Fr. Álvaro da Cunha, entre outros. Os iluminadores que terão colaborado com Álvares Seco seriam Duarte Fernandes, Jorge Vieira, António Vaz Bugalho e António de Holanda, conhecendo-se os contratos de iluminação de livros firmados com alguns destes artistas.

A maioria dos seus livros está organizada segundo determinados parâmetros. Geralmente, um longo título principia as suas obras. Seguia-se o alvará régio que preconizava a execução da obra; depois o modo de proceder do autor e uma dedicatória ao rei; em seguida, o prólogo às partes que compõem a obra; títulos e sumários antecedem, frequentemente, as transcrições dos documentos; o índice das matérias, no início ou no fim; e, por último, o termo de encerramento feito pelo escrivão, onde por vezes intervém o próprio autor. São precisamente os sumários, e os textos mais ou menos longos, que antecedem a transcrição das escrituras, ou a explicitação dos capítulos, que refletem o pensamento, os conhecimentos e, consequentemente, as intenções de Pedro Álvares Seco subjacentes à sua produção histórica.

As suas obras estão impregnadas de citações bíblicas e de recursos à Sagrada Escritura, referências a autores de direito civil, e canónico, citações de escritores e poetas, de filósofos gregos, teólogos, pontífices, ainda de vidas de santos, revelando também conhecimentos históricos, geográficos e científicos. Cita provérbios, escreve vocábulos em grego para explicar a origem etimológica de certas palavras, demonstra

19 GODINHO, Vitorino Magalhães- "O naufrágio da memória nacional e a nação no horizonte de marketing”. In BETHENCOURT, Francisco; RAMADA CURTO, Diogo (ed.) - A Memória da Nação. Lisboa: Livraria Sá da Costa, 1991, pp. 15-28. 
conhecimento de ofícios artesanais e emite considerações de caráter mais pessoal. $\mathrm{O}$ cronista demonstra ainda ter o cuidado de rever as suas obras para evitar erros e corrigilos antes de se tornarem públicas. As principais limitações das suas obras estão associadas ao desconhecimento do $\mathrm{X}$ aspado e alguma confusão na datação de diplomas pontifícios, formulando, consequentemente, incorreções históricas.

O quarto capítulo intitula-se "Pedro Álvares Seco: a organização da memória da Ordem de Cristo", que dividimos em dois grupos: a memória económico-patrimonial e a memória histórico-institucional. Constatamos que, num primeiro momento, é pedido ao cronista que fixe a dimensão patrimonial da Ordem; no entanto, a partir da anexação das três Ordens à Coroa, em dezembro de 1551, é notória a intenção histórico-institucional impressa às suas concretizações. No primeiro caso, foram incluídos os tombos de bens e propriedades relativos ao extenso património da Ordem, e que refletem a dimensão patrimonial da instituição. No segundo caso, estão integrados os livros que atestam os direitos e privilégios que, ao longo da sua história, a Ordem de Cristo foi acumulando, e que recebeu tanto de pontífices, como de monarcas, ou de outras entidades. Todos estes livros espelham a meticulosa organização documental do cronista.

O quinto capítulo, "Pedro Álvares Seco: ciclos de produção documental", reflete toda a obra do cronista, dividida por quatro ciclos, estabelecidos a partir dos alvarás que preconizaram as obras. Do $1^{\circ}$ ciclo - 1530 - data o alvará para proceder à demarcação e inventário dos bens do convento e mesa mestral, dando início aos seus registos. $\mathrm{Na}$ sequência dos alvarás do $2^{\circ}$ ciclo -1542 - o cronista iniciou seis tombos de bens e um livro de escrituras. Dos alvarás do $3^{\circ}$ ciclo - 1559/60 - resultaram quatro livros relativos às comendas e às escrituras da Ordem. Finalmente, do $4^{\circ}$ ciclo - década de 1570 identificámos mais 4 livros sobre as igrejas e a normativa da Ordem. No cronograma que se segue, é possível identificar todas essas obras e respetivos alvarás. 


\begin{tabular}{|c|c|c|c|c|c|c|c|c|c|c|c|}
\hline \multirow{2}{*}{ Alvarás e obras } & \multirow{2}{*}{\begin{tabular}{|l|}
1530 \\
$1^{\circ}$ Ciclo
\end{tabular}} & 1542 & \begin{tabular}{|l|}
$1540-$ \\
1550
\end{tabular} & \multirow[t]{2}{*}{ 1550- } & \multirow{2}{*}{\multicolumn{3}{|c|}{\begin{tabular}{|l|l|}
$3^{\circ}$ Ciclo & 1570 \\
\end{tabular}}} & \begin{tabular}{|l|}
1571 \\
\end{tabular} & \begin{tabular}{|l|}
$1570-$ \\
1579
\end{tabular} & 1579 & \begin{tabular}{|l|}
$1579-$ \\
1581
\end{tabular} \\
\hline & & & $2^{\circ}$ Ciclo & & & & & \multicolumn{4}{|c|}{$4^{\circ}$ Ciclo } \\
\hline \multicolumn{12}{|l|}{\begin{tabular}{|l|} 
Alvará para proceder à \\
demarcação e inventário dos \\
bens do convento e mesa \\
mestral
\end{tabular}} \\
\hline \multicolumn{12}{|l|}{$\begin{array}{l}\text { Alvará para fazer tombo das } \\
\text { propriedades do convento, } \\
\text { igrejas e mesa mestral } \\
\end{array}$} \\
\hline \multicolumn{12}{|l|}{$\begin{array}{l}\text { Começo e preâmbulo do } \\
\text { tombo dos bens, rendas, } \\
\text { direitos e escrituras do } \\
\text { Convento de Tomar }\end{array}$} \\
\hline \multicolumn{12}{|l|}{$\begin{array}{l}\text { Tombo de bens do convento } \\
\text { de Tomar }\end{array}$} \\
\hline \multicolumn{12}{|l|}{$\begin{array}{l}\text { Tombo de bens da mesa } \\
\text { mestral }\end{array}$} \\
\hline \multicolumn{12}{|l|}{$\begin{array}{l}\text { Tombo da igreja de Santa } \\
\text { Maria dos Olivais }\end{array}$} \\
\hline \multicolumn{12}{|l|}{$\begin{array}{l}\text { Tombo dos bens das capelas } \\
\text { do convento de Tomar }\end{array}$} \\
\hline \multicolumn{12}{|l|}{$\begin{array}{l}\text { Tombo dos bens da Gafaria da } \\
\text { Misericórdia de Tomar }\end{array}$} \\
\hline \multicolumn{12}{|l|}{$\begin{array}{l}\text { Livro das Escrituras do } \\
\text { Hospital de Santa Maria da } \\
\text { Graça de Tomar }\end{array}$} \\
\hline \multicolumn{12}{|l|}{$\begin{array}{l}\text { Alvará para Damião de Góis } \\
\text { mandar entregar a Pedro } \\
\text { Álvares os traslados de bulas e } \\
\text { breves }\end{array}$} \\
\hline \multicolumn{12}{|l|}{$\begin{array}{l}\text { Alvará para Pero de Alcáçova } \\
\text { Carneiro mandar entregar a } \\
\text { Pedro Álvares os traslados de } \\
\text { bulas e breves }\end{array}$} \\
\hline \multicolumn{12}{|l|}{$\begin{array}{l}\text { Livro de bulas e letras } \\
\text { apostólicas concedidos à } \\
\text { Ordem de Cristo }\end{array}$} \\
\hline \multicolumn{12}{|l|}{$\begin{array}{l}\text { Alvará que ordena a } \\
\text { realização do Livro das } \\
\text { Escrituras da Ordem de Cristo }\end{array}$} \\
\hline \multicolumn{12}{|l|}{$\begin{array}{l}\text { Alvará que ordena a } \\
\text { realizacâao do Livro das } \\
\text { Comendas da Ordem de } \\
\text { Cristo }\end{array}$} \\
\hline \multicolumn{12}{|l|}{$\begin{array}{l}\text { Alvará que ordena que as } \\
\text { despesas com a realização dos } \\
\text { livros sejam pagas com os três } \\
\text { quartos do convento }\end{array}$} \\
\hline \multicolumn{12}{|l|}{$\begin{array}{l}\text { Compêndio das Comendas da } \\
\text { Ordem de Cristo }\end{array}$} \\
\hline \multicolumn{12}{|l|}{$\begin{array}{l}\text { Livro das Comendas da } \\
\text { Ordem de Cristo }\end{array}$} \\
\hline \multicolumn{12}{|l|}{$\begin{array}{l}\text { Livro das Escrituras da Ordem } \\
\text { de Cristo }\end{array}$} \\
\hline \multicolumn{12}{|l|}{$\begin{array}{l}\text { Livro dos sumários das } \\
\text { Escrituras da Ordem de Cristo }\end{array}$} \\
\hline \multicolumn{12}{|l|}{$\begin{array}{l}\text { Alvará que ordena a } \\
\text { realização do Livro das } \\
\text { Igrejas e Padroados da Ordem } \\
\text { de Cristo }\end{array}$} \\
\hline \multicolumn{12}{|l|}{$\begin{array}{l}<\text { Summa do que se contém } \\
\text { no }>\text { Livro das igrejas }\end{array}$} \\
\hline \multicolumn{12}{|l|}{$\begin{array}{l}\text { Livro das Igrejas e Padroados } \\
\text { da Ordem de Cristo }\end{array}$} \\
\hline \multicolumn{12}{|l|}{$\begin{array}{l}\text { Alvará que ordena a } \\
\text { realizacão do Livro da Regra e } \\
\text { Definiçōes da Ordem de } \\
\text { Cristo } \\
\end{array}$} \\
\hline $\begin{array}{l}\text { Livro da Regra e Definições } \\
\text { da Ordem de Cristo }\end{array}$ & & & & & & & & & & & \\
\hline
\end{tabular}

Cronograma 1 - A produção documental de Pedro Álvares Seco decorrente dos alvarás régios. 
No quinto capítulo, o mais extenso da tese, é feita uma reflexão detalhada sobre cada uma das 15 obras da chancela de Álvares Seco. A atribuição da autoria a Pedro Álvares não implica que o próprio tenha assumido as tarefas de amanuense, mas sim, que o próprio reúna em si a autoridade de conceção e de validação de um trabalho em que participaram vários escrivães e iluminadores. Os códices que se conhecem da autoria de Pedro Álvares Seco, entre originais e cópias, estão dispersos por diferentes arquivos e bibliotecas. Na Torre do Tombo localizámos 13 destes códices; na Biblioteca Nacional de Portugal estão depositadas sete obras; no Arquivo Distrital de Santarém encontra-se um documento original; no Arquivo da Misericórdia de Tomar há dois livros; e na Biblioteca Nacional de Espanha localizámos a sua última realização.

Algumas são obras de grande beleza e harmonia estética, como mostram algumas das imagens feitas: uma miniatura representando a charola do convento de Tomar; letras iniciais ornadas; cercaduras com motivos fitomórficos e zoomórficos, e com as armas e divisa de D. Manuel enquanto rei e administrador da Ordem de Cristo, e cuja linguagem artística é particularmente dignificante para o seu possuidor.

No capítulo seis, "Pedro Álvares Seco: entre o registado e o esquecido", fazemos um balanço entre a documentação registada pelo cronista e a que ele não copiou, e que se encontrou registada em outras fontes consultadas. Pedro Álvares fez copiar quase duas mil escrituras, relativas às Ordens do Templo e de Cristo, com especial ênfase para a documentação relativa a esta última, o que se explica por ser a instituição sobre a qual incide o seu trabalho. Há documentos repetidos em vários livros, e até no mesmo livro, o que revela uma intencionalidade do autor, por vezes com contornos nítidos, noutras menos distintos, cujo objetivo poderia passar por querer destacar determinada informação ou por considerar que a mesma poderia ser enquadrada em mais do que uma categoria no contexto organizativo da sua obra. Podemos ainda pensar que a distância temporal que separa muitos manuscritos também poderia justificar a repetição de algumas escrituras. A elaboração de vários gráficos sistematiza a informação recolhida. Num segundo momento analisámos a "documentação não selecionada: intencionalidade ou lapso?", o que implicou a consulta e o confronto com inúmeras fontes manuscritas e impressas. Se, por um lado, se compreende que Pedro Álvares não tenha registado sentenças contrárias às Ordens ou diplomas pontifícios que cerceavam privilégios das 
milícias, por outro é difícil explicar por que motivos não terá o cronista incluído importantes documentos fundacionais das Ordens, como textos normativos e diplomas pontifícios que confirmam a nomeação dos governadores da Ordem de Cristo. Desconhecimento? Estariam na posse dos seus proprietários? É o próprio cronista que afirma que muitas escrituras respeitantes à Ordem não foram depositadas no cartório, o que dificultaria ainda mais o acesso às mesmas; em determinado momento também lamenta que procurou muitas outras, e não as encontrou. Num terceiro momento, é feito o balanço entre o registado e o esquecido, ficando claro que Pedro Álvares Seco regista, preferencialmente, documentos que exaltam e enriquecem, patrimonial e institucionalmente, tanto a Ordem do Templo, como a Ordem de Cristo. Em contrapartida, omite, intencionalmente ou não, documentos cujas determinações e sentenças são contrárias às Ordens. Por lapso, desconhecimento, ou simplesmente por não the ter sido concedido o acesso, não registou documentação que, na nossa perspetiva, contribuía com elementos fundamentais para a história da instituição.

No capítulo sete "Do convento de Tomar à dispersão das obras de Pedro Álvares Seco", tentámos averiguar o percurso das obras do cronista desde o convento de Tomar até às bibliotecas e arquivos onde se encontram atualmente. Revelou-se um exercício arriscado e impossível de concretizar com a máxima exatidão, pois apenas se sabe o local de partida e o de chegada. Fenómenos naturais, como incêndios e terramotos, aliados ao impacto da desamortização das Ordens Religiosas em Portugal e às sucessivas catalogações da documentação explicam o desaparecimento de muitos tesouros escritos portugueses.

Em conclusão, constatamos que a primeira preocupação do cronista, e do rei promotor da obra, foi registar uma memória, eminentemente, de caráter patrimonial da Ordem de Cristo, de forma a que o rei, paralelamente administrador da instituição, tivesse pleno conhecimento dessa dimensão. No final, fica evidente que o que está implícito é uma clara exaltação não só da Ordem de Cristo, mas também do poder régio enquanto modelador da própria instituição e patrocinador do projeto historiográfico levado a cabo por Pedro Álvares Seco, e que o cronista pretende projetar para o futuro. O cunho discursivo e historiográfico que imprimiu às suas obras assume-se em estreita ligação com a retórica do poder régio, impulsionador desta produção. $\mathrm{O}$ cronista apostou na 
dialética entre os poderes seculares e temporais, entre o Mestre e o Rei, que, no caso da Ordem de Cristo, é assumida pela mesma pessoa. Como tal, Pedro Álvares Seco saiu claramente vencedor projetando a sua obra ao longo de mais de cinco séculos.

Acrescente-se que, em anexo foi incluída uma tabela que enumera todas as comendas e os comendadores da Ordem de Cristo no século XVI, feita com base no Livro das Comendas da Ordem de Cristo (1563), de Pedro Álvares Seco. Anexaram-se também as transcrições de três documentos, em função da sua pertinência relativamente à obra do cronista e à história da Ordem de Cristo. O primeiro é um documento de 28 de outubro de 1319, segundo o qual D. Dinis manda restituir a D. Gil Martins, Mestre da Ordem de Cristo, todos os bens que foram da Ordem do Templo. O segundo é um diploma pontifício de Inocêncio VIII, a bula "Romanus pontifex" de 3 de maio de 1487, que confirma D. Manuel, duque de Beja, como governador da Ordem de Cristo, e que a par da transcrição é incluída a tradução pelo Dr. Manuel Ramos, professor da Faculdade de Letras. E o terceiro, de 23 de julho de 1523, é um documento que descreve a tomada de posse do mestrado de Cristo por D. João III, como seu administrador, na igreja de S. Tomás do convento de Tomar perante mais de uma centena de freires.

Pelo estudo desenvolvido, pelos documentos inéditos apresentados, pelos novos dados coligidos, pelas reflexões aduzidas e pelas conclusões alcançadas, esperamos, humildemente, ter contribuído para enriquecer a investigação científica sobre a Ordem de Cristo em Portugal. 


\section{COMO CITAR ESTE ARTIGO}

\section{Referência electrónica:}

LENCART, Joana - "Pedro Álvares Seco: a retroprojeção da memória da Ordem de Cristo no século XVI". Medievalista 26 (Julho-Dezembro 2019). [Em linha] [Consultado dd.mm.aaaa]. Disponível em http://www2.fcsh.unl.pt/iem/medievalista/MEDIEVALISTA26/lencart2613.html ISSN 1646-740X.

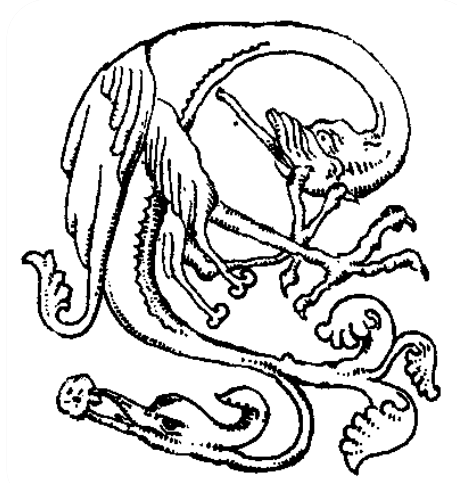

